ORIGINAL ARTICLE

\title{
A Critical Analysis of Vitamin D and Calcium in Women during Pregnancy
}

MUHAMMAD ABBAS ${ }^{1}$, SHAZIA AZHAR ${ }^{2}$, ASHER FAWWAD ${ }^{3}$, HINA ABBAS ${ }^{4}$, HUMAIRA JABEEN ${ }^{5}$, FAZZILAT KAMAL ${ }^{6}$, MUHAMMAD SOHAIL ${ }^{7}$

${ }^{1}$ Senior Technologist, Patel Hospital Laboratory Karachi

${ }^{2}$ Assisstant Professor \& Deputy Director, Baqai Institute of Medical Technology, Baqai Medical University Karachi

${ }^{3}$ Professor \& Head of Biochemistry, Baqai Medical University Karachi

${ }^{4}$ Senior Lecturer, Baqai Institute of Medical Technology, Baqai Medical University Karachi

${ }^{5}$ Vice Principal, National Institute of Physical Therapy \& Rehabilitation Karachi

${ }^{6}$ Consultant Consultant, Darul Shifa Medical Center \& Maternity Home Karachi

${ }^{7}$ Medical Technologist, DHQ Hospital, Lakki Marwat

Correspondence to: Dr. Shazia Azhar E-mail: shaziahashem@gmail.com Cell 0332-3383315

\begin{abstract}
Aim: To find out the frequency of vitamin $D$ and calcium in pregnant women and their effects on fetus as well as mothers.

Study Design: Retrospective study.

Place and Duration of Study: Darul Shifa Clinic \& Maternity Home Karachi Pakistan from $1^{\text {st }}$ July 2020 to $31^{\text {st }}$ December 2020.

Methodology: One hundred and twenty patients with proper evidence of pregnancy were enrolled. All patients from age 18 years to age 35 years with no other disease were included and those women who have some other diseases or age outliers were excluded.

Results: There is a significance difference in the vitamin $\mathrm{D}$ and calcium during the period of pregnancy. In the group $A$ (18 years to 25 years) the significance difference of vitamin $D$ was $(P=0.000)$ while the calcium was $(P=0.200)$. In the group $B$ (26 years to 30 years) the significance difference of vitamin $D$ was $(P=0.000)$ while the Calcium was ( $P=0.071)$ and in the group $C$ (30 years to 35 years) there was no significant change of vitamin $D$ and calcium $(P=0.000)$. The result of group $C$ is different from the results of the above two groups, because in this age majority of the women were living in a congested houses as well as were spending a depressive life due to home problems, husband wife compromise problems, children problems, financial problems etc. and all such problems have a direct impact on their pregnancy

Conclusion: It was statistically found that the Vitamin D and calcium values show significances changes during pregnancy in contrast to the normal women.

Key words: Vitamin D, Calcium, Pregnant women
\end{abstract}

\section{INTRODUCTION}

Pregnancy is a physiological state during which developing fetus totally depends on mother for nutrition. During this period the requirement of nutrients and other supplements like calcium, vitamins, iron and folic acid significantly increase. During the time of pregnancy 30 grams of calcium is transmitted in to fetus. Due to which numerous physiological/biological modifications occur in mother body to provide such amount of calcium like increase intestine absorption of calcium, increase reabsorption from bones and decrease urinary calcium excretion. ${ }^{1}$

Calcium and vitamin $\mathrm{D}$ are extremely beneficial for both mother and baby during pregnancy span. The insufficient amount of calcium and vitamin D can lead to a number of problems during pregnancy. ${ }^{2}$ Vitamin $D$ is elevated when maternal kidney 1alpa hydroxylase enzyme are elevated. ${ }^{3}$ There is an increased risk of preeclampsia, gestational diabetes mellitus, smallness for gestation infant and pre term birth due to vitamin $D$ deficiency. ${ }^{4}$

Extreme deficiency of Vitamin $D$ in pregnancy may lead to severe illness in both fetus and mother. Decreased weight gain and pelvic deformities that prevent normal vaginal delivery in pregnancy is also a cause of Vitamin $D$ deficiency. Maternal vitamin D deficiency is linked with neonatal problems comprising hypocalcaemia, with or without convulsions rickets and defective tooth enamel.
The full-term fetal skeleton comprises of round about $30 \mathrm{~g}$ of calcium with the majority of accretion happening in the third trimester, whereas feeding women secrete approximately $280-400 \mathrm{mg} /$ day of calcium in breast milk., ${ }^{2,5}$

Round about five percent of the pregnant females have preeclampsia, defined as hypertension and proteinuria starting in the second half of gestation. Preeclampsia is a primary reason of maternal death throughout the world and is accompanied by substantial perinatal morbidity and mortality. ${ }^{6}$

The deficiency of vitamin $D$ during pregnancy is related with many short and long span problems in neonates, such as multiple sclerosis, rickets in children, recurrent wheezing, type I diabetes, weakness of internal immune system, vitamin D deficiency in infants, and smallness for gestational age (SGA). According to earlier studies, using supplements in pregnancy is essential to increase the serum levels of calcium and vitamin $D$ in mothers and neonates. The results of 13 clinical trials $3-15$ and several meta-analyses $16-20$ have suggested that calcium supplementation reduces the incidence of preeclampsia. ${ }^{7-9}$

Vitamin $\mathrm{D}$ has a momentous role in the development of skeletal muscles, Immune system; cell differencing having protein like nerves growth factor in the CNS. In recent times the vitamin $D$ has been concerned as a threat 
factor for diabetes, IHD ${ }^{10}$ and TB in Asians. ${ }^{11}$ Low maternal vitamin $D$ may adversely affect the developing fetal brain. In addition to the previously known pediatric problems of hypocalcaemic fits, dental enamel hypoplasia, infantile rickets, and congenital cataracts in early life, vitamin D deficiency has been shown to affect postnatal head and linear growth. ${ }^{12}$

In the United Kingdom, the Committee on Medical Aspects of Food Policy (COMA) recommended that all newborns receive $7-8.5 \mu \mathrm{g}(280-340 \mathrm{IU})$ of vitamin $D$ daily either in a multivitamin preparation or in fortified infant formula milk. It recommends that all pregnant and lactating mothers should receive $10 \mu \mathrm{g}(400 \mathrm{IU})$ of vitamin D daily ${ }^{13}$ and advises that Asian children should be encouraged to take vitamin D supplements throughout the first five years of life. Several researches consequently reported that infants of mothers with low vitamin D intake during pregnancy had low serum calcium concentrations in cord blood or during the first week of life. ${ }^{14,15}$ Also, it may be possible that maternal vitamin $D$ status affects fetal growth and bone development. ${ }^{16,17}$

The level of vitamin $D$ is the major key for pregnant female and calcium level of her fetus, low level of vitamin D and calcium is to be consider the primary factor of rickets, osteomalacia, poor development of CNS system etc. ${ }^{18,19}$ This problem is not only restricted to pregnant ladies from Pakistan, however there are reports of a high occurrence of low vitamin $D$ position amongst pregnant women in the Middle East, Pakistan, India and Ethiopia. ${ }^{20}$

In a population where there is already has a high prevalence of vitamin $D$ insufficiency and poor nutritional calcium intake, the problem is likely to worsen during the period of pregnancy because of the active transplacental transport of calcium to the developing fetus. Hypovitaminosis D in pregnancy has vital consequences for the newborn comprising of fetal hypovitaminosis D, neonatal rickets and tetany and infantile rickets. ${ }^{21,22}$ The inadequate amount of Calcium as well as vitamin $D$ can cause a number of problems in the pregnant women as well as in the fetus like underdeveloped growth, a reduced peak bone density increasing the risk of osteoporosis and some problems of CNS system later in life. ${ }^{23}$

During pregnancy the developing baby is totally dependent upon the calcium store in the mother body due to which the mother's bones and teeth are always at risk, and the developing fetus needs a proper amount of calcium for a better survival. $30 \mathrm{~g}$ of calcium is required to a normal fetal skeleton by the end of $2^{\text {nd }}$ trimester while $80 \%$ of the calcium accretion is occurred during the third trimester in pregnancy. This means that in the third trimester the normal fetal required $250-300 \mathrm{mg}$ of calcium. ${ }^{24}$

Vitamin $\mathrm{D}$ derived from both diet and sunlight. Mainly the vitamin $D$ derives from sunlight and the lack of expose to sunlight is the main cause of vitamin D deficiency. ${ }^{25-27}$ Calcium is the main mineral for both genders, it is especially imperative to the health of females. As the women get older they start losing calcium form bones. So keeping sufficient level during this period is serious to escape major skeletal problem. ${ }^{28}$ Sun light plays a key role in vitamin $D$ for performing different types of functions in the body. The 25-hydroxylase helps to metabolizes vitamin
D3 in to 25-hydroxy vitamin D3 the activated form of vitamin D. ${ }^{29}$

\section{MATERIALS AND METHODS}

This retrospective study was conducted at Darul Shifa Clinic \& Maternity Home Karachi Pakistan from $1^{\text {st }}$ July 2020 to $31^{\text {st }}$ December 2020 and comprised 120 different gestational age women between 18 to 35 years. Patients from any other hospital because of the time insufficiency were excluded. The frequency of vitamin $D$ and calcium were calculated by the SPSS version 20 .

\section{RESULTS}

The vitamin $\mathrm{D}$ was significantly deficient while the ratio of the calcium was normal in majority of the cases during pregnancy. In group one, $18-25$ years showed vitamin D mean value gain was $11.6 \pm 10.939$ and $P=0.000$. Whereas in calcium the mean value was $7.463 \pm 0.200$ and $P=0.200$. In the second age group from $26-30$ years vitamin $D$, the mean was $13.3 \pm 7.667$ and $P=0.000$ while in calcium, the mean was $7.902 \pm 0.980$ and $P=0.071$. In third age group from 31-35 years vitamin $D$, mean was $20.3 \pm 15.790$ and $\mathrm{P}=0.000$ whereas in calcium, the mean was $8.47 \pm 0.919$ and $P=0.000$. These results shows significant deficiency of vitamin $D$ in all three groups but the ratio of calcium was not deficient because of taking calcium supplements during this span. The results of group third was different from the results of the above two groups which shows both vitamin $\mathrm{D}$ as well as Calcium also deficient between 31-35 years (Table 1).

Table 1: Comparison of age according to vitamin $D$ and calcium

\begin{tabular}{|l|l|l|l|}
\hline Age (years) & Vitamin D & Calcium & P value \\
\hline $18-25$ & $11.6 \pm 10.93$ & $7.46 \pm 1.0$ & 0.000 \\
\hline $26-30$ & $13.3 \pm 7.66$ & $7.90 \pm 0.98$ & 0.071 \\
\hline $31-35$ & $20.3 \pm 15.79$ & $8.47 \pm 0.19$ & 0.00 \\
\hline
\end{tabular}

\section{DISCUSSION}

The vitamin $D$ and calcium are the essential parameters in the period of pregnancy. Nobody can deny this truth that human body is the combination of different systems (digestive, urinary, reproductive, Respiratory, muscular etc) having their own specific role for a healthy survival, but unfortunately nowadays there is a catastrophic lack of the balance diet due to which human life is facing serious problems in their routine life, in which calcium and vitamin $D$ is on the peak. ${ }^{30}$

According to a research conducted in Iran in 2007 stated that vitamin $\mathrm{D}$ and calcium are the vital parameters for a better survival in general and playing a key role in the women during pregnancy. This showed that vitamin $D$ concentration of pregnant women is lower than the normal women and a stress is also given to the use of sufficient amount of calcium and vitamin D supplements intake during pregnancy is important. ${ }^{31}$

The concentration of vitamin $D$ and calcium was significant greater than the women seen as non-pregnant. Some other studies also mentioned that women who attained the vitamin $\mathrm{D}$ during pregnancy had a greater head circumference as compared to those who did not receive vitamin $D$, and the deficiency of vitamin $D$ may have sever variations in pregnancy outcomes. ${ }^{32}$ 
The mean score of vitamin $D$ was $11.6 \pm 10.939$ and mean score of calcium was $7.463 \pm 1.102$ and $P=0.200$. There is a significant lack of vitamin $D$ in the first group having ages from 18 to 25 years. Whereas there is no significant lack of calcium was found in this group. In the current study a great correlation was found with the previous studies. Maghbooli et $\mathrm{al}^{31}$ reported that vitamin $\mathrm{D}$ is continuously lower in the first three to eight months of pregnancy in the age of $19-30$ years. Kazemi et $\mathrm{al}^{33}$ also observed a high prevalence of physiologically significant hypovitaminosis D among pregnant women in Iranian population. This study showed that the mean score of vitamin $D$ was $13.3 \pm 7.667$ and the mean score of calcium was $7.902 \pm 0.980(P=0.071)$ in second age group. So this interpretation clearly demonstrates that there is a significant lack of vitamin $D$ in the $2^{\text {nd }}$ group having ages from 26 to 30 years. Whereas there is no significant lack of calcium was found in this group. Because normally both vitamin $D$ and calcium is deficient during pregnancy but here the researcher achieved normal result of calcium just due to the taking of calcium supplement and proper care of the subject during this span.

Karim et $\mathrm{al}^{34}$ conducted a study in a tertiary-care center Karachi, Pakistan reported that vitamin D deficiency is high among pregnant urban Pakistani women and their newborns. According to the current study, the age between 31-35 years, the mean score of vitamin D was $20.3 \pm 15.790$ and mean score of calcium was $8.47 \pm 0.919$ and the value of significance was 0.000 . So this analysis clearly proves that there is a significant lack of vitamin $D$ and calcium in the $3^{\text {rd }}$ group having ages from 31 to 35 years.

\section{CONCLUSION}

Vitamin $D$ and calcium are the key standards that need proper care and attention during pregnancy and there is a significant lack of vitamin D especially in women whereas for eliminating the deficiency of calcium, majority of them are taking supplements for better out comes. The proper care, attention, balanced diet and peaceful environment should be provided to the women during pregnancy so that they spend their life in peace not in piece.

\section{REFERENCES}

1. Pitkin RM. Calcium metabolism in pregnancy and the perinatal period: a review. Am J Obstet Gynecol 1985;151(1): 99-109.

2. Mohammad-Alizadeh-Charandabi S, Mirghafourvand M, Mansouri A Najafi M, Khodabande $F$. The effect of vitamin $D$ and calcium plus vitamin $D$ during pregnancy on pregnancy and birth outcomes: a randomized controlled trial. J Caring Sci 2015;4(1):35.

3. Turner M, Barre PE, Benjamin A, Goltzman D, Gascon-Barre M. Does the maternal kidney contribute to the increased circulating 1 25-dihydroxyvitamin D concentrations during pregnancy? Mineral Electrolyte Metab 1988;14(4):246-52.

4. Wei SQ, Audibert F, Hidiroglou N, Sarafin K, Julien P, Wu Y, et al. Longitudinal vitamin $D$ status in pregnancy and the risk of pre-eclampsia. BJOG 2012;119(7):832-9.

5. Mohammad-Alizadeh-Charandabi S, Mirghafourvand M, Mansouri A, Najafi M, Khodabande $F$. The effect of vitamin $D$ and calcium plus vitamin $D$ during pregnancy on pregnancy and birth outcomes: a randomized controlled trial. J Caring Sci 2015;4(1):35.

6. Cunningham FG, Lindheimer MD. Hypertension in pregnancy. NEJM 1992; 326(14):927-32.

7. Levine RJ, Hauth JC, Curet LB, Sibai BM, Catalano PM, Morris CD, et al. Trial of calcium to prevent preeclampsia. NEJM 1997;337(2):6977.

8. Dersimonian RE. Meta-analysis in the design and monitoring of clinical trials.Statistics in medicine. 1996 Jun 30;15(12):1237-48.
9. Goldsmith LA, Bolognia JL, Callen JP, Chen SC, Feldman SR, et al. American Academy of Dermatology Consensus Conference* on the safe and optimal use of isotretinoin: summary and recommendations. J Am Acad Dermatol 2004;50(6):900-6.

10. Boucher BJ. Inadequate vitamin D status: does it contribute to the disorders comprising syndrome ' $X$ '? Br J Nutr 1998; 79:315-27.

11. Wilkinson RJ, Llewelyn $M$, Toossi $Z$, et al. Influence of vitamin D deficiency and vitamin $D$ receptor polymorphisms on tuberculosis among Gujarati Asians in west London: a case control study. Lancet 2000;355:618-21.

12. Brunvand L, Quigstad E, Urdal P, Haug E. Vitamin D deficiency and fetal growth. Early Hum Dev 1996;45:27-33

13. Congdon P, Horsman A, Kirby PA, Dibble J, Bashir T: Mineral content of the forearms of babies born to Asian and white mothers. BMJ 1983, 286:1234-5.

14. Marya RK, Rathee S, Lata V, Mudgil S: Effects of vitamin D supplementation in pregnancy. Gynecol Obstet Invest 1981, 12: 15561.

15. Paunier L, Lacourt G, Pilloud P, Schlaeppi P, Sizonenko PC: 25 Hydroxyvitamin $D$ and calcium levels in maternal, cord and infant serum in relation to maternal vitamin D intake. Helv Paediatr Acta1978, 33:95-103.

16. Moncrieff M, Fadahunsi TO: Congenital rickets due to maternal vitamin D deficiency. Arch Dis Childhood 1974, 49:810-811.

17. Nozza JM, Rodda CP. Vitamin D deficiency in mothers of infants with rickets. Med J Aust 2001, 3:253-5.

18. Dijkstra $\mathrm{SH}$, van Beek A, Janssen JW, de Vleeschouwer LH, HuysmanWA, van den Akker EL. High prevalence of vitamin D deficiency in newborns of high-risk mothers. Arch Dis Chld Fetal Neonatal Ed 2007:92:750-53.

19. Munns C, Zacharin MR, Rodda CP, et al. Prevention and treatment of infant and childhood vitamin D deficiency in Australia and New Zealand. Med J Aust 2006; 185:268-72.

20. Delvin EE, Salle BL, Glorieux FH, Adeleine P, David LS. Vitamin D supplementation during pregnancy: effect on neonatal calcium homeostasis. J Pediatr 1986; 109:328-34.

21. Purvis RJ, Barrie WJ, MacKay GS, et al. Enamel hypoplasia of the teeth associated with neonatal tetany: a manifestation of maternal vitamin D deficiency. Lancet 1973; 2:811-4.

22. Boucher BJ. Inadequate vitamin D status: does it contribute to the disorders comprising syndrome 'X'? Br J Nutr 1998; 79:315-27.

23. Brunvand L, Shah SS, Bergstrom S, Hang E. Vitamin D deficiency in pregnancy is not associated with obstructed labour: a study among Pakistani women in Karachi. Acta Obst Gynecol Scand 1998;77:3036.

24. Clemens TL, Adams JS, Henderson SL, Clemens TL, Adams JS, Henderson SL, et al. Increased, skin pigment reduces the capacity of skin to synthesize vitamin D3. Lancet 1982; 174-76.

25. Harris SS, Dawson-Hughes B. Seasonal changes in plasma 25hydroxyvitamin $\mathrm{D}$ concentrations of young American black and white women. Am J Clin Nutr 1998;67: 1232-6.

26. Mishal AA. Effects of different dress styles on vitamin D levels in healthy young Jordanian women. Osteoporosis Int 2011; 12: 931-5.

27. Holick MF. Sunlight and vitamin D for bone health and prevention of autoimmune diseases, cancers and cardiovascular disease. Am J Clin Nutr 2004; 80:(6 Suppl): 1678S-88.

28. Zeni SN, OrtelaSoler CR, Lazzari A, et al. Interrelationship between bone turnover markers and dietary calcium intake in pregnant women: a longitudinal study. Bone 2003;33:606-13.

29. Norman AW, Roth J, Orci L. The vitamin D endocrine system: steroid metabolism, hormone receptors and biological response. Endocrine Rev 1982;3:331-66.

30. Hollis BW, Wagner CL. Assessment of dietary vitamin D requirements during pregnancy and lactation. Am J Clin Nutr 2004; 79(5): 717-26.

31. Maghbooli Z, Hossein-Nezhad H, Shafaei AR, Karimi F, SadatMadani $F$, et al. Vitamin $D$ status in mothers and their newborns in Iran. BMC Pregnancy Childbirth 2007; 7:1.

32. Okonofua F, Menon RK, Houlder S, Thomas M, Robinson D, O'Brien $S$, Dandona P. Calcium, vitamin D and parathyroid hormone relationships in pregnant Caucasian and Asian women and their neonates. Ann Clin Biochem 1987; 24: 22-8.

33. Kazemi A, Sharifi F, Jafari N, Mousavinasab N. High prevalence of vitamin $\mathrm{D}$ deficiency among pregnant women and their newborns in an Iranian population. Womens Health (Larchmt) 2009;18(6): 835-9.

34. Karim SA, Nusrat $U$, Aziz S. Vitamin D deficiency in pregnant women and their newborns as seen at a tertiary-care center in Karachi, Pakistan. Int J Gynaecol Obstet 2011; 112(1): 59-62. 